\title{
Effects of metabolic control on bone mineral density and markers of bone remodeling in adult patients with Type 1 Diabetes Mellitus
}

\author{
Eleftheria Barmpa ${ }^{1}$, Spyros Karamagiolis², SteliosTigas ${ }^{3}$, Parthena Navrozidou ${ }^{4}$, Marianna Vlychou ${ }^{4}$, Ioannis Fezoulidis ${ }^{4}$, Georgios ${ }^{2}$ \\ Koukoulis ${ }^{1}$, Alexandra Bargiota ${ }^{1}$

\begin{abstract}
${ }^{1}$ Department of Endocrinology and Metabolic Diseases, University of Thessaly, Larissa, Greece
${ }^{2}$ General Hospital of Larissa, Larissa, Greece

${ }^{3}$ Department of Endocrinology, University of loannina, loannina

${ }^{4}$ Department of Radiology, Faculty of Medicine, University of Thessaly, Larissa, Greece
\end{abstract}

\section{OBJECTIVES}

Type 1 diabetes mellitus (T1DM) is associated with reduced bone mineral density (BMD) and increased bone turnover. However, data regarding the influence of glycemic control on bone are limited. The aim of this study was to evaluate BMD and bone remodeling markers in patients with T1DM in relation to changes in glycemic control.

\section{METHODS}

We studied: - 107 patients with T1DM (Group-D) (mean age: 34+8.1 years, M/F: 48/59)

- 95 healthy controls (Group-C) matched for age, sex and body mass index (BMI)

Patients in Group-D were re-examined after one year follow-up (FU)

In both groups were measured:

- Glycated hemoglobin (HbA1c)

- Lumbar spine (LS) and femoral neck (FN) were determined by dual energy X-ray absorptiometry (DXA) (Hologic Discovery QDR Series Densitometer, Hologic Inc., Bedford, MA)

- Bone resorption assessed by $\beta$-crosslaps

- Bone formation assessed by serum levels of type 1 procollagen total $\mathrm{N}$ terminal propeptide (TP1NP)

(Elecsys 1010/2010/MODULAR ANALYTICS E170)

Fifty patients from Group-D re-examined after a year and had the same measurements as baseline

- BMD changes at LS more than $3 \%$ and at FN more than $6 \%$ were considered to be significant

\section{RESULTS}

\section{Results of group $D$ and $C$ at baseline}

\section{Anthropometric characteristics}

\begin{tabular}{|l|c|c|c|}
\hline & D & C & p-value \\
\hline $\mathrm{N}$ & 107 & 95 & 0.083 \\
\hline Sex $(\mathrm{M} / \mathrm{F})$ & $48 / 59$ & $45 / 50$ & \\
\hline Age $(\mathrm{y})$ & $34 \pm 8.1$ & $34.8 \pm 7.9$ & 0.091 \\
\hline Duration of DM $(\mathrm{y})$ & $15.1 \pm 7.4$ & - & \\
\hline BMI $\left(\mathrm{kg} / \mathrm{m}^{2}\right)$ & $23.2 \pm 2.2$ & $23.1 \pm 1.9$ & 0.096 \\
\hline WC $(\mathrm{cm})$ & $94.5 \pm 9.6$ & $92.9 \pm 8.7$ & 0.24 \\
\hline HbA1c $(\%)$ & $8.2 \pm 1.3$ & $5.1 \pm 0.4$ & 0.023 \\
\hline
\end{tabular}

\section{Blood tests}

\begin{tabular}{l|c|c|c|} 
& D & C & p-value \\
\hline$\beta$-crosslaps & $317.6 \pm 9.3$ & $322.1 \pm 8.7$ & 0.071 \\
\hline TP1NP & $47.4 \pm 5.1$ & $48.9+4.6$ & 0.067
\end{tabular}

FN BMD by DXA

\section{LS BMD by DXA}

\begin{tabular}{|c|c|c|c|}
\hline & D & C & $p$-value \\
\hline $\begin{array}{l}\text { Total BMD } \\
\left(\mathrm{g} / \mathrm{cm}^{2}\right)\end{array}$ & $1.024 \quad 0.201$ & $\begin{array}{lll}1.052 & 0.143\end{array}$ & 0.041 \\
\hline Total z-score & $-0.3 \pm 1.5$ & $1.0 \pm 1.5$ & 0.032 \\
\hline Total T-score & $-0.3 \quad 1.6$ & 0.91 .7 & 0.024 \\
\hline
\end{tabular}

\begin{tabular}{l|c|c|c|} 
& D & C & p-value \\
\hline BMD FN $\left(\mathrm{g} / \mathrm{cm}^{2}\right)$ & $0,6960,121$ & $0,8980,112$ & 0.042 \\
\hline Z-score FN & $-0.1 \pm 1.4$ & $1.4 \pm 0.8$ & 0.041 \\
\hline T-score FN & $-0,1 \pm 1,5$ & $1,41,0$ & 0.038 \\
\hline BMD Total $\left(\mathrm{g} / \mathrm{cm}^{2}\right)$ & $0.743 \pm 0.132$ & $0.967 \pm 0.098$ & 0.044 \\
\hline Total Z-score & $0.0 \pm 1.5$ & $1.5 \pm 0.9$ & 0.043 \\
\hline Total T-score & $0.0 \pm 1.3$ & $1.6 \pm 0.7$ & 0.046 \\
\hline
\end{tabular}

At baseline:

Positive correlation was observed between the age of patients and Z-score at both LS and FN $(r=0.32, p=0.023$ and $r=0.24$, $p=0.018$, respectively)

The early-onset of T1DM was positive correlated with Z-score at both LS and $\mathrm{FN}(\mathrm{r}=0.17, \mathrm{p}=0.044$ and $r=0.29, p=0.021$, respectively)

> Patients with lower BMI showed a lower Z-score of both LS and FN $(r=0.27, p=0.031$ and $r=0.28$, $p=0.022$, respectively)

Negative correlation was observed between LS BMD and $\mathrm{HbA1c}$ $(r=-0,21, p=0,041)$

\section{At Group D, after one vear (FU):}

$>$ Group-DR: $36 / 50$ patients had $>0.5 \%$ reduction in $\mathrm{HbA} 1 \mathrm{c}$

$>$ Group-DS: $8 / 50$ had about the same HbA1c

$>$ Group-DI: $6 / 50$ had $>0.5 \%$ increase in $\mathrm{HbA} 1 \mathrm{c}$

* DS and DI were small in number of patients to reach a safe and reliable conclusion

\section{At Group-DR was observed the following changes:}

\begin{tabular}{|c|c|c|c|}
\hline & Baseline & 1 year FU & Change \\
\hline BMD LS $\left(\mathrm{g} / \mathrm{cm}^{2}\right)$ & 1.0240 .201 & $1.058 \pm 0.207$ & $3,3 \%$ \\
\hline BMD FN $\left(\mathrm{g} / \mathrm{cm}^{2}\right)$ & $0,696 \quad 0,121$ & $0.739+0.128$ & $5,6 \%$ \\
\hline
\end{tabular}

TP1NP

\section{CONCLUSIONS}

$\checkmark$ T1DM is associated with reduced BMD

$\checkmark$ However, improvement of glycemic control appears to ameliorate BMD and bone turnover and could help to stabilize the bone mass in these patients

$\checkmark$ Identifying the factors that affect bone in patients with T1DM can help to improve the health of their bones

\section{References}

Gudrun Leidig-Bruckner1,2*,et al., Prevalence and determinants of osteoporosis in patients with type 1 and type 2 diabetes mellitus BMC Endocrine Disorders 2014

Masahiro Yamamoto, Insights into bone fragility in diabetes: the crucial role of bone quality on skeletal strength, Endocrine Journal 2015, 62 (4), 299-308

\section{응 88--GP} 总

\section{Diabetes 2}

Alexandra Bargion 